\title{
Glomerulonephritis in sarcoidosis: causal relationship unproven
}

\author{
R.S. Howard ${ }^{1}$ and Roger Gabriel ${ }^{2}$ \\ ${ }^{1}$ Brompton Hospital, London SW3 and ${ }^{2}$ St Mary's Hospital, London W2 1NY, UK
}

Summary: Two patients with sarcoidosis and glomerular mesangial proliferative lesions are described. Although a causative relationship between sarcoidosis and glomerulonephritis has been suggested, critical review of the literature fails to confirm this.

\section{Introduction}

The most common cause of renal involvement in sarcoidosis is hypercalcaemia which may predispose to nephrocalcinosis, nephrolithiasis and renal tubular abnormalities. ${ }^{1-5}$ Less frequently described is interstitial granulomatous nephritis. ${ }^{6-12}$ Glomerulonephritis has also been reported in association with sarcoidosis but a causal relationship has never been established.

\section{Patients}

\section{Patient 1}

A 41 year old Pakistani man visited his home country after living in Britain for 11 years. He developed a fever and on investigation bilateral hilar lymphadenopathy was found. A 30 month course of anti-tuberculous chemotherapy was given. In early 1981 he returned to England where, on chest X-ray, sarcoidosis was diagnosed and chemotherapy was discontinued. Fever recurred two years later and hepatosplenomegaly with generalized sarcoid skin lesions over the trunk and legs were noted. Investigations revealed normal chest X-ray and respiratory function tests; proteinuria of $2 \mathrm{~g}$ daily, hypercalcinuria of $8.9 \mathrm{mmol} /$ day and serum angiotensin converting enzyme (SACE) 3 times the upper limits of normal. Skin biopsy showed non-caseating epitheloid and giant cell granulomas. A Kveim test was positive. Symp-

Correspondence: R.S. Howard, Ph.D., M.R.C.P., Department of Neurology, St Bartholomew's Hospital, West Smithfield, London EC1A 7BE, UK.

Accepted: 8 July 1991 toms subsided without treatment but returned after

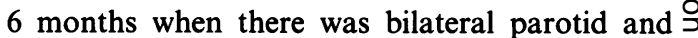
submandibular gland enlargement and hepato- $\vec{r}$ splenomegaly. The proteinuria had doubled, creatinine clearance was $80 \mathrm{ml} / \mathrm{min}$, SACE activity unchanged and the complement profile was normal.

Renal biopsy showed mild diffuse increase mesangial matrix with some focal and segment宊 mesangial proliferation. There were multiple interstitial non-caseating epithelioid and giant cell granulomas. Immunoperoxidase studies showed diffuse mesangial IgM, IgG, Clq and C3. Electron $\stackrel{\odot}{\stackrel{\circ}{\varrho}}$ microscopy confirmed the light microscopic find- $\overrightarrow{\vec{P}}$ ings and demonstrated incomplete foot process obliteration of visceral epithelial cells. There were no electron-dense deposits.

A 2 year course of prednisolone began in November 1983 and he showed considerable im- 3 provement. When last seen in March 1989 he was clinically well, his proteinuria had resolved, serum creatinine was $85 \mu \mathrm{mol} / 1$ and SACE was normal.

\section{Patient 2}

A 50 year old Ghanian woman presented in 1982 with a maculopapular eruption around the chin and right nasolabial fold. Biopsy showed lupus $\%$ pernio. There were no other systemic symptoms $\mathbb{O}$ and chest X-ray was normal. Six months of $\mathrm{N}^{N}$ methotrexate led to considerable resolution of the 0 lesions. In February 1985 the lupus pernio recurred. Routine urine examination showed proteinuria of $1.3 \mathrm{~g} /$ day with a creatinine clearance of $\stackrel{\oplus}{\rightleftharpoons}$ $55 \mathrm{ml} / \mathrm{min}$. Chest X-ray was normal, serum IgG 0 was elevated at $15.3 \mathrm{~g} / \mathrm{l}$, the complement profile ${ }_{0}$ showed mild elevation of haemolytic and C4 $\stackrel{\odot}{\odot}$ activity but C3 was normal. Renal histology $\mathbb{D}$ 
showed a segmental increase in mesangial cells and an increase in mesangial matrix. In two glomeruli segmental thickening of the capillary walls and Bowman's capsule was present. The interstitium showed small scattered foci of fibrosis with moderately dense mononuclear cell infiltration. Immunoperoxidase showed scattered fine granular localization of $\mathrm{IgM}+, \mathrm{Clq}+, \mathrm{C} 3+$ and $\mathrm{IgG} \pm$ in the mesangium. Electron microscopy confirmed the light microscopic findings; there were electrondense deposits in the mesangial matrix and focal loss of foot processes of some visceral epithelial cells.

She was treated with prednisolone $5 \mathrm{mg}$, azathioprine $50 \mathrm{mg}$ and cyclophosphamide $50 \mathrm{mg}$ daily. When last seen in March 1990 she was clinically well and renal function had become normal with a serum creatinine of $108 \mu \mathrm{mol} / 1$ and a $24 \mathrm{~h}$ urine protein of $0.8 \mathrm{~g} /$ day.

\section{Discussion}

Glomerulonephritis has occasionally been reported in association with sarcoidosis. The most common abnormal glomerular morphologies are membranous, mesangiocapillary, focal sclerosis, IgA nephropathy, chronic and non-specific glomerulonephritides. ${ }^{13-31}$ In one patient crescentic proliferative glomerulonephritis recurred following transplantation. ${ }^{24}$

Several authors (D.G. James, unpublished observations cited in References 22 and 24) have noted that the relative infrequency of glomerulonephritis as a manifestation of sarcoid causes uncertainty as to whether the coincidence of the two conditions is fortuitous or causally related. Many serious criticisms may be levelled at sporadic case reports purporting to suggest a causal relationship but without providing any aetiopathological evidence.

In a number of earlier case reports the renal pathology was inadequately studied, poorly documented $^{28,32}$ or obtained from post mortem tissues ${ }^{33}$ making interpretation of glomerular change difficult. We agree with Taylor et al..$^{22}$ that in several publications the descriptions of renal morphology are apparently at variance with the claims of the authors, the appearances described being more suggestive of membranoproliferative rather than proliferative and mesangioproliferative glomerulonephritis. ${ }^{18,30}$ In other reports abnormalities such as hypercalcaemia, nephrolithiasis or nephrocalcinosis often co-existed with minor glomerular changes. ${ }^{19,32,34}$ Further, prolonged periods often existed between the development of active sarcoid and the glomerulonephritis and vice versa. ${ }^{15,19,22,23}$ Of the 33 cases reported and reviewed by Taylor et al. ${ }^{22} 10$ patients developed sarcoidosis up to 18 years before the glomerulonephritis and in 6 patients the renal disease presented up to 10 years before the sarcoid. In many of the reported cases there is little or no evidence of active sarcoid at the onset of glomerulonephritis. ${ }^{16,22}$ Also, critical review of the histology in a number of early papers $^{2,3,21,25,27-29,33,35-39}$ is impossible because renal morphology was in the process of development, details of glomerular change are too sparse, immunofluorescent or immunoperoxidase studies were not reported and electron microscopy was not performed. Without these complementary techniques an adequate analysis of a renal biopsy is not possible. ${ }^{40}$ Perhaps one centre should collect blocks of tissue from the various reporting laboratories to provide an overall uniform histological diagnosis and immunoperoxidase studies. ${ }^{41}$

Both of our patients presented with sarcoidosis, had proteinuria of presumed glomerular origin and had IgM associated mesangioproliferative lesions. This glomerular histology is not uncommon, the aetiology is unknown and not linked to any recognized clinical picture. ${ }^{42}$ Therefore, in our patients, as in those previously reported, it is impossible to establish a causal relationship between sarcoid and glomerulonephritis.

\section{Acknowledgements}

We wish to thank Dr D.M. Geddes for permission to publish details of patient 1, Dr D. Mitchell for his invaluable advice and Professor K.A. Porter for providing details of the renal biopsies.

\section{References}

1. Scadding, J.G. \& Mitchell, D. Sarcoidosis. 2nd ed. Chapman and Hall, London, 1985, pp. 390-413.

2. Klatskin, G. \& Gordon, M. Renal complications of sarcoid and their relationship to hypercalcaemia. Am J Med 1953, 15: 484-498.

3. Scholtz, D.A. \& Keating, F.R. Renal insufficiency, renal calculi and nephrocalcinosis in sarcoidosis: report of eight cases. Am J Med 1956, 21: 75-84.

4. Muther, R.S., MacCarrion, D.A. \& Bennett, W.M. Renal manifestations in sarcoidosis. Arch Int Med 1981, 141: 643-645.
5. Johns, C.J., Scott, P.P. \& Schonfield, S.A. Sarcoidosis. Ann Rev Med 1989, 40: 353-371.

6. VanDorp, W.T., Jie, K., Lobatto, S., Weening, J.J. \& Valentijn, R.M. Renal failure due to granulomatous interstitial nephritis after pulmonary sarcoidosis. Nephrol Dial Transplant 1987, 2: 573-575.

7. Cuppage, F.E., Emmott, D.F. \& Duncan, K.A. Renal failure secondary to sarcoidosis. Am J Kid Dis 1988, 6: 519-520.

8. Farge, D., Liote, F. \& Turner, M. Granulomatous nephritis and chronic renal failure in sarcoidosis. Am J Nephrol 1986, 6: 21-27. 
9. Williams, P.F., Thomson, D. \& Anderton, J.L. Reversible renal failure due to isolated renal sarcoidosis. Nephron 1984, 37: 246-249.

10. Allegri, L., Olivetti, G. \& David, S. Sarcoid granulomatous nephritis with isolated and reversible renal failure. Nephron 1980, 25: 207-208.

11. Bolton, W.K., Atuk, N.O. \& Rametta, C. Reversible renal failure from isolated granulomatous renal sarcoidosis. Clin Nephrol 1976, 5: 88-92.

12. Korzets, Z., Schneider, M., Taragan, R. et al. Acute renal failure due to sarcoid granulomatous infiltration of the renal parenchyma. Am J Kid Dis 1985, 6: 250-253.

13. Falls, W.F., Randall, R.G. \& Sommers, S.C. et al. Nonhypercalcaemic sarcoid nephropathy. Arch Int Med 1972, 130: 285-291.

14. McCoy, R.C. \& Tisher, C.C. Glomerulonephritis associated with sarcoidosis. Am J Path 1972, 68: 339-353.

15. Lee, S.M. \& Michael, A.F. Focal glomerular sclerosis and sarcoidosis. Arch Path Lab Med 1978, 102: 572-575.

16. Taylor, R.T., Senekjian, H.O., Knight, T.F., Gyorky, F. \& Weinman, E.J. Membranous nephropathy with epithelial crescents in a patient with pulmonary sarcoidosis. Arch Int Med 1979, 139: 1183-1185.

17. Goldszer, R.C., Galvenek, E.C. \& Lazarus, J.M. Glomerulonephritis in a patient with sarcoidosis. Arch Path Lab Med 1981, 105: 478-481.

18. Waldek, S., Agius Ferrante, A.M. \& Lawler, W. Renal failure due to glomerulonephritis in sarcoidosis. $\mathrm{Br}$ Med J 1978, 1: $1110-1111$.

19. McSerragh, E.T., Twomey, M. \& Doyle, C.T. Sarcoidosis with renal involvement. Postgrad Med J 1978, 54: 528-532.

20. Salomon, M.I., Poon, T.P., Hsu, K.C., King, E.J. \& Tehertkoff, V. Membranous glomerulopathy in a patient with sarcoidosis. Arch Path 1975, 99: 479-483.

21. Correa, P. Sarcoidosis in association with glomerulonephritis. Arch Path 1954, 57: 523-529.

22. Taylor, R.G., Fisher, C. \& Hoffbrand, B.I. Sarcoidosis and membranous glomerulonephritis: a significant association. Br Med J 1982, 284: 1297-1298.

23. Mariani, A.F., Clifton, S. \& Davies, D.J. et al. Membranous glomerulonephritis associated with sarcoidosis. Aust $N Z J$ Med 1978, 8: 420-425.

24. Beaufils, H., Pompel, A., Gubler, M.C., Lucsko, M. \& Guedon, J. Pre- and posttransplant glomerulonephritis in a case of sarcoidosis. Nephron 1983, 35: 124-129.

25. Berkman, J.L. \& Bernstein, S.H. Membranous glomerulonephropathy in association with sarcoidosis. In: Proceedings of the 3rd International Congress of Nephrology, Washington. Karger, Basel, 1966.

26. Godin, M., Fillastre, J.P., Ducastelle, T., Hemet, J., Morere, P. \& Nouvet, G. Sarcoid retroperitoneal fibrosis, renal artery involvement and unilateral focal glomerulosclerosis. Arch Int Med 1980, 140: 1240-1242.
27. Laroche, C., Merillon, H., Morel-Maroger, L. et al. Synd- ڤొ rome nephrotique avec glomerulite extramembraneuse $>$ associee a une sarcoidose. J Urol Nephrol 1968, 74:995-1002. (D)

28. Teilium, G. Glomerular lesions of the kidney in sarcoidosis. Acta Pathol Microb Scand 1951, 28: 294-301.

29. Etienne-Martin, P., Klepping, C., Guerrin, J., Barthes, H., $\overrightarrow{\vec{F}}$ Bine, J. \& Duserre, L. Syndrome nephrotique au cours d'une $\stackrel{\text { ? }}{+}$ maladie de Besinier-Boeck-Schumann a localisation pul- $\bigcirc$ monaire, osseuse et hepatique. J Med Lyon 1962, 43: 흐 193-198.

30. Briner, J. \& Gartmann, J. Glomerulonephritis bei sarkoidose. Schweiz Med Wochenschr 1978, 108: 401-406.

31. Vidal, F., Oliver, J.A., Companya, E., Baguer, A., Carrera, ญ M. \& Richart, C. Sarcoidosis presenting as multiple pulmonary nodules and nephrotic syndrome. Postgrad Med $J \vec{O}$ 1986, 62: 1147-1149.

32. Lebacq, E., Verhaegen, H. \& Desmet, V. Renal involvement $\vec{\omega}$ in sarcoidosis. Postgrad Med J 1970, 46: 526-529.

33. Longcope, W.T. \& Frieman, D.G. A study of sarcoidosis based on a combined investigation of 160 cases including 30 autopsies from The Johns Hopkins Hospital and Massachusetts General Hospital. Medicine 1952, 31: 1-132.

34. Gabriel, R., Orton, E. \& Joekes, A.M. Hypervitaminosis D, anaemia and renal failure. Postgrad Med J 1970, 46: ๒ 455-457.

35. Ricker, W. \& Clark, M.A. A clinicopathological review of 300 N cases including 22 autopsies. Am J Clin Path 1949, 19: 725-749.

36. Lofgren, S., Snellman, B. \& Lindgren, A.G.H. Renal comp- lications in sarcoidosis. Acta Med Scand 1957, 159: 295-305.

37. Berger, R.W. \& Relman, A.S. Renal impairment due to sarcoid infiltration of the kidney. $N$ Engl J Med 1955, 252: 44-49.

38. Sorger, K. \& Taylor, W.A. Generalised sarcoidosis. Report $\& \vec{\theta}$ a fatal case terminating in fatal nephropathy. Arch Path 1960 71: $35-43$.

39. Ogilvie, R.I., Kaye, M. \& Moore, S. Granulomatous sarco disease of the kidney. Am J Med 1964, 42: 273-277.

40. Appendix: Processing and examination of renal biopsies. In Churg, J. \& Sobin, L.H. (eds) Renal Disease: Classification and Atlas of Glomerular Disease. Igaku-Shoin, Tokyo, New York, 1982, pp. 345-350.

41. Sinclair, R.A., Burns, J. \& Dunnill, M.S. Immunoperoxidase staining of formalin fixed, paraffin embedded, human renal biopsies with a comparison of the peroxidase-antiperoxidase (PAP) and indirect methods. $J$ Clin Path 1981, 34: 345-350.

42. Mampaso, F., Gonzalo, A., Teruel, J. et al. Mesangial deposits of IgM in patients with the nephrotic syndrome. Clin Nephrol 1981, 16: 230-234. 